\title{
The Seroprevalence Study of Reticuloendotheliosis Virus Infection in Chicken in Bangladesh
}

\author{
M. Zulfekar Ali \\ Animal Health Research Division, Bangladesh Livestock Research Institute (BLRI), Savar, \\ Dhaka-1341, Bangladesh.
}

\begin{abstract}
$\mathbf{W}$ E SHOWED seroprevalence of Reticuloendotheliosis virus (REV) in poultry in selected areas of Bangladesh.Total 3,555 serum samples were collected between 2014 and 2016 from 10 districts, 6 types of chicken and 144 flocks, tested for the specific antibodies directed against REV by indirect Enzyme Linked Immunosorbent Assay (ELISA). The overall seroprevalence of REV in the chickens tested were $21.13 \%(751 / 3,555)$ and $73.61 \%(106 / 144)$ flocks were seropositive. According to district, Gazipur had the highest (49.50\%) and Khulna had the lowest $(9.09 \%$ ) seropositive rates.Additionally, the prevalence rates were highest $38.21 \%$ during onset of laying period, age between 19 and 24 weeks. The positivity rates were almost same round the year like $22.96 \%$ in summer, $20.70 \%$ in rainy and $20.43 \%$ in winter seasons. Furthermore, the seropositive rates in broiler flocks, broiler breeder flocks, commercial layer flocks, layer breeder flocks, sonali flocks, and domestic chicken flocks were $6.86 \%, 42.15 \%$, $25.84 \%, 33.59 \%, 9.40 \%$, and $6.49 \%$, respectively. Conclusion: These results indicate that REV infections are widespread ubiquitous in all types of chickens and may appear as a potential threat for the rapidly growing poultry industry in Bangladesh. This is the first seroprevalencestudy on REV infections in chicken in Bangladesh.More prevalence study, molecular characterization and vaccine production from local isolates are emergency requirements to combat REV. The quality verification of imported vaccine must be strongly adopted.
\end{abstract}

Keywords: Reticuloendotheliosis, REV, Seroprevalence, Antibody, Chicken, Indirect ELISA.

\section{Introduction}

Reticuloendotheliosis virus (REV) belongs to the genus gammaretrovirusis an immunosuppressive and oncogenic virus of avian species [1-3]. REVaffects the wide range of avian species including chickens, turkeys, goose, ducks, pheasants, peafowl, quails, Hungarian Partridges, Attwater's prairie chickens and Chinese Partridges [2, 4-6]. REV can cause immunesuppression, lymphoma and runting disease [3], and clinically showed nodular tumors in the liver, lung, kidney, pancreas, and retarded the normal growth of birds [7]. REV has worldwide distribution including India, neighbor country of Bangladesh[8, 9]. Several studies also identified the incorporation of REV provirus in the genome of fowlpox virus[10, 11]. As a result, REV might be transmitted through fowlpox vaccine as contamination [1012]. Presently, there are no effective drugs or vaccines available to control REV infections in poultry farms [3]. Serological survey against REV has already been reported by many countries and found $3.3-25 \%$ seropositive rates, but any constructive studies in Bangladesh are absent [13]. Thus, it is imperative to conduct the more research on seroprevalence and molecular epidemiology of REV to protect the rising poultry industry of Bangladesh. The present study is aimed to focus the seroprevalence of REV in chickens from selected areas of Bangladesh by indirect Enzyme Linked Immunosorbent Assay (ELISA).

\section{Materials and Methods}

\section{Chicken flocks}

Six different types of chicken flocks, including broiler, broiler breeder, layer, layer breeder, Sonali and domestic chicken raised in 10 districts were sampled.Except domestic chicken flocks and broiler chicken flocks all types of chicken flocks were vaccinated according to regular vaccine schedule, like the use of live turkey herpes virus with live Marek's disease (MD) virus serotype 3 at 0 days old. Then subsequently use live fowlpox vaccine at $37^{\text {th }}$ days. The health condition of the selected flocks was considered as normal due to a weekly mortality rate of 0 to $0.15 \%$. 


\section{Serum samples}

The serological investigation was conducted during 2014 to 2016 in 10 districts of Bangladesh (Fig. 1). Serum samples were divided into 10 age groups from 1- 60 weeks of age with 6 weeks interval as well as divided year seasons, including summer, rainy and winter.

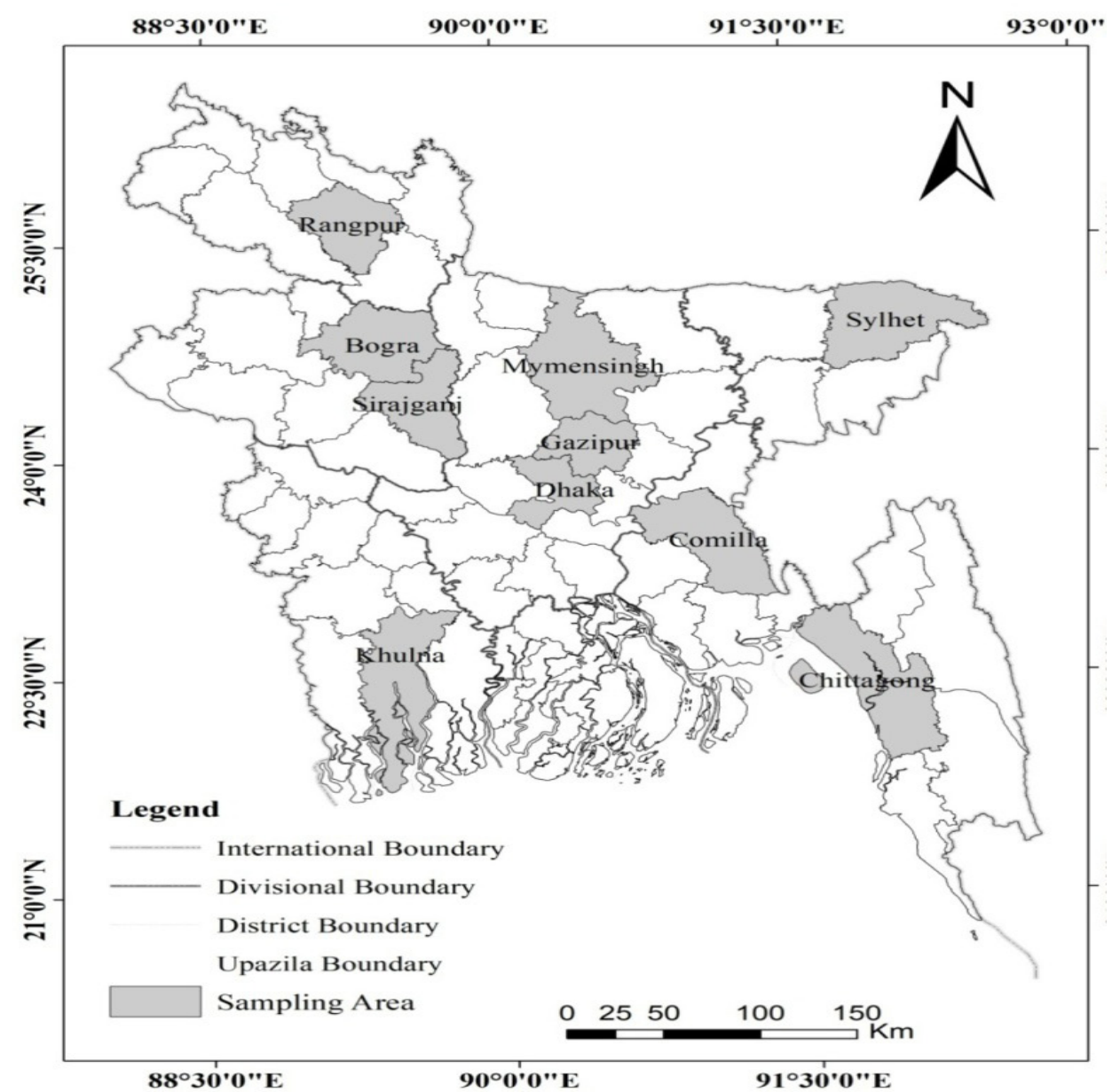

Fig. 1. Bangladesh Map showing locations of 10 districts where samples were collected. The map was created by using Geographic Information Systems (GIS) software ESRI ArcGIS version 10.2.1.

Total 3555 serum samples were collected from 144 chicken flocks of 6 types of chickenincluding broiler flocks, broiler parent flocks, layer flocks, layer parent flocks, sonali chicken flocks, and domestic chicken flocks to detect specific antibodies directed against REV virus infection. About 20-30 blood samples set werecollectedfrom each flock. The ages of the chickens of selected flocks were 1 to 60 weeks.

The $1.5 \mathrm{ml}$ blood samples were collected from wing vein of each chicken with the help of $3 \mathrm{ml}$ disposable plastic syringe. Then bloodsamples were allowed to clot at room temperature for 1hour by placing in undisturbed condition with $45^{\circ}$ angles. Then serum was decanted in clear tubes and centrifuged at $21000 \times g$ for 5 minutes at $4^{\circ} \mathrm{C}$ temperature for collecting clear serum. Then the serum was transferred to sterilized eppendorf tubes and stored at $-80^{\circ} \mathrm{C}$ until serological testing [3].

\section{ELISA test}

All sera samples were tested for specific antibodies against REV by indirect ELISA test with a commercially available ELISA kit. The ELISA test was performed according to manufacturer's instructions $\left(\right.$ BioChek $^{\circledR}$, Netherlands). The absorbance of controls and samples were recorded by reading at $405 \mathrm{~nm}$. Sera with sample/positive $(\mathrm{S} / \mathrm{P})$ ratios above the cut-off value of 0.5 or greater (titer $\geq 0.501$ ) were considered positive. 


\section{Results}

Testing samples were collected over the year of 2014 to 2016 . Total3,555 serum samples belonging to 144 different flocks, 106 (73.61\%) flocks were seropositive for REV antibodies. Overall seroprevalence of REV in individual chicken tested was $21.13 \%$ (751/3555). The distribution of REV seroprevalencein sampled flocks raised in ten districts of Bangladesh is shown in Fig. 1. The highest seroprevalence $49.50 \%(198 / 400)$ was found in Gazipurand the lowest $9.09 \%$ (28/308) found in the samples of Khulna district. For the rest 8 districts, it was $21.84 \% 83 / 380$ ) in Rangpur, $15.99 \%$ (63/394) in Chattogram, $14.15 \%$ (45/318) in Dhaka, $19.81 \%$ $(85 / 429)$ in Sylhet, $14.16 \%$ (49/346) in Sigajganj, $22.96 \%$ 87/379) in Bogura, $12.96 \%$ (35/270) in Comilla and $23.56 \%$ (78/331) in Mymensingh district (Table 1).

TABLE 1. Seroprevalence of REV ELISA positive samplesin chicken flocks raised in different districts of Bangladesh

\begin{tabular}{lcccc}
\hline \multirow{2}{*}{ S1. No. } & Sampling area & \multirow{2}{*}{ (Districts) } & Tested Sample & \multicolumn{2}{c}{ Results } \\
\cline { 4 - 5 } & Rangpur & 380 & 83 & Positive samples \\
2 & Khulna & 308 & 28 & 21.84 \\
3 & Chattogram & 394 & 63 & 15.99 \\
4 & Dhaka & 318 & 45 & 14.15 \\
5 & Sylhet & 429 & 85 & 19.81 \\
6 & Sirajganj & 346 & 49 & 14.16 \\
7 & Bogura & 379 & 87 & 22.96 \\
8 & Comilla & 270 & 35 & 12.96 \\
9 & Mymensingh & 331 & 78 & 23.56 \\
10 & Gazipur & 400 & 198 & 49.50 \\
\hline \multicolumn{2}{c}{ Total } & $\mathbf{3 , 5 5 5}$ & $\mathbf{7 5 1}$ & $\mathbf{2 1 . 1 3}$ \\
\hline
\end{tabular}

Regarding chicken age groups, At 1-6 weeks old, the seropositive rate was $9.55 \%(64 / 640)$, after that the seroprevalencewas gradually increased and reached up to the highest rate of $38.21 \%(162 / 424)$ at the age of 19 to 24 weeks. After $24^{\text {th }}$ weeks the rate of seropositive were
$29.01 \%(150 / 517)$ at $25-30$ weeks, $21.99 \%$ $(64 / 291)$ at $31-36$ weeks, $26.54 \%(112 / 422)$ at $37-42$ weeks, $37.11 \%(59 / 159)$ at $43-48$ weeks, $13.76 \%(15 / 109)$ at $49-54$ weeks, and $19.53 \%$ $(67 / 343)$ at 55-60 weeks of age (Fig. 2).

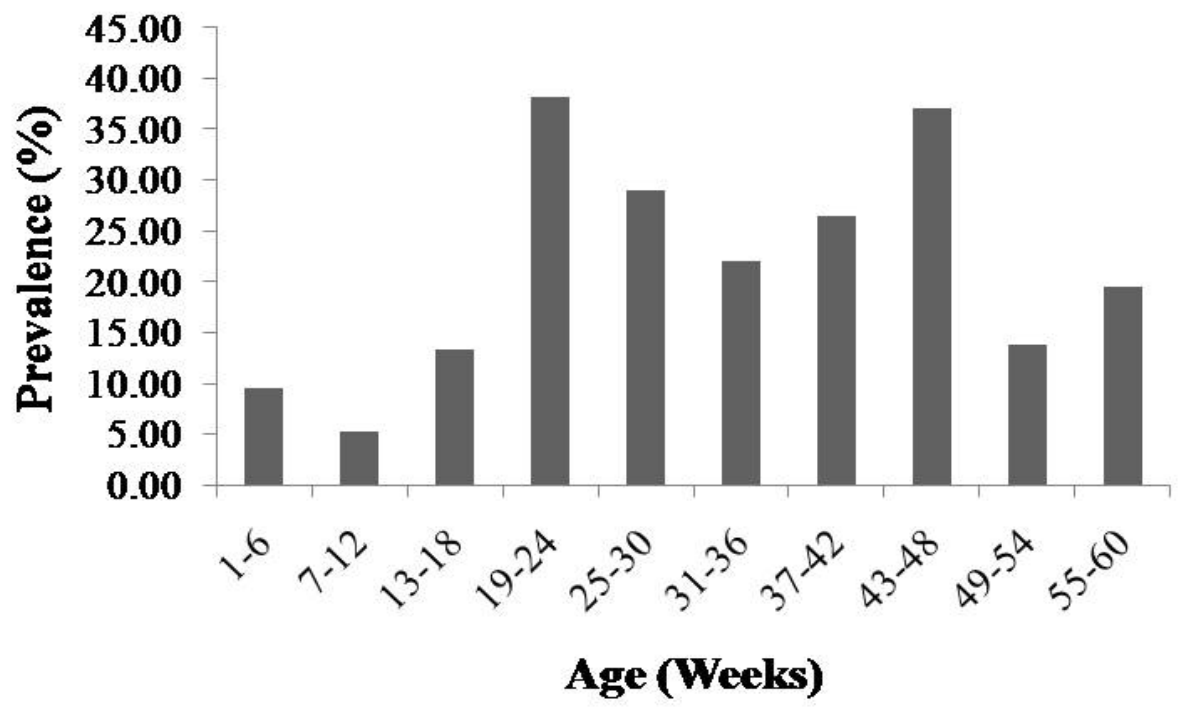

Fig. 2. Seroprevalence of REV ELISA positive samplesin differentchicken flocks ages groups. 
Furthermore, tested serum samples from different chicken flocks, counting broiler, broiler breeder, layer, layer breeder, sonali and domestic chicken showed REV seropositive rates $6.86 \%$ (26/379), 42.15\% (314/745), 25.84\% (123/476), $33.59 \%(174 / 518), 9.40 \%(67 / 713)$ and $6.49 \%$ (47/724), respectively (Fig.3).
REV positive rate in samplesin year seasons, including summer, rainy and winter were $22.96 \%$ $(186 / 810), \quad 20.70 \%(320 / 1546)$ and $20.43 \%$ (245/1199), respectively (Fig. 4).

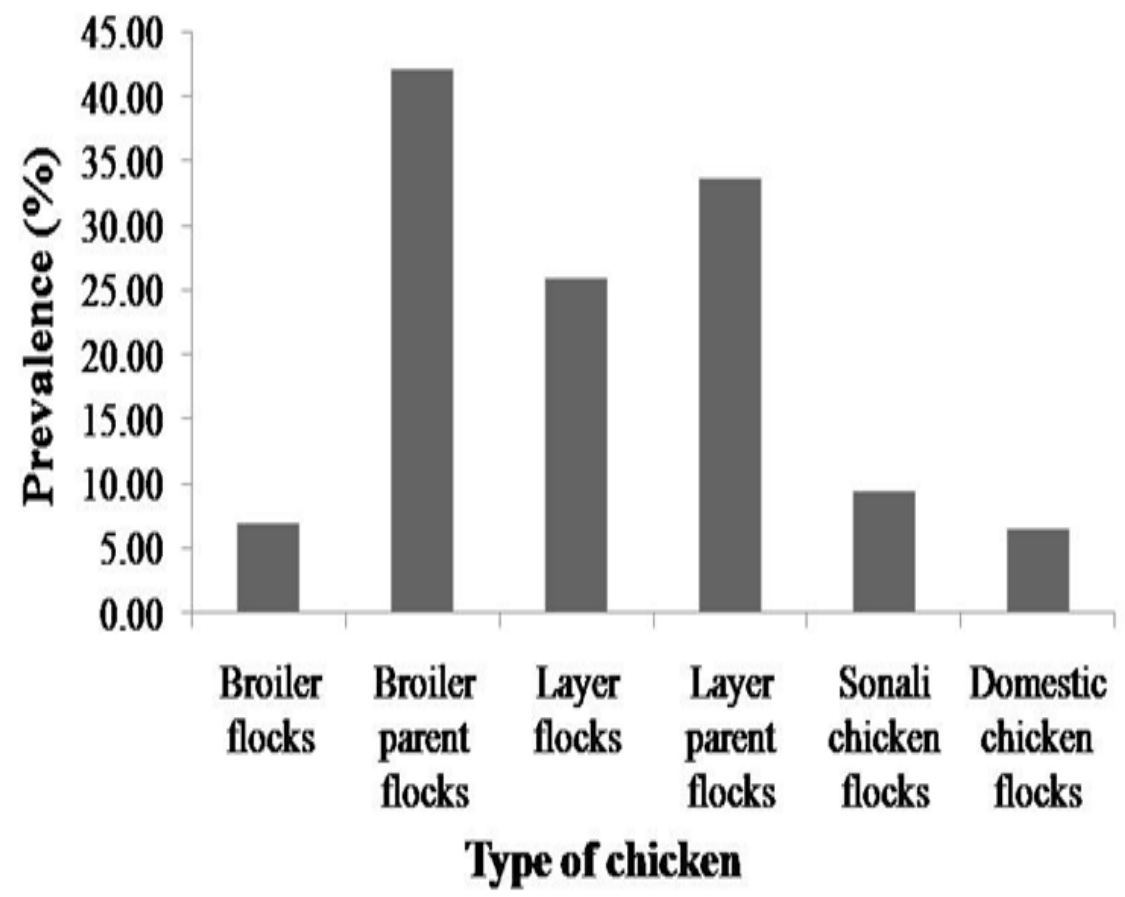

Fig. 3.Seroprevalence of REV ELISA positive samplesin different type chicken flocks.

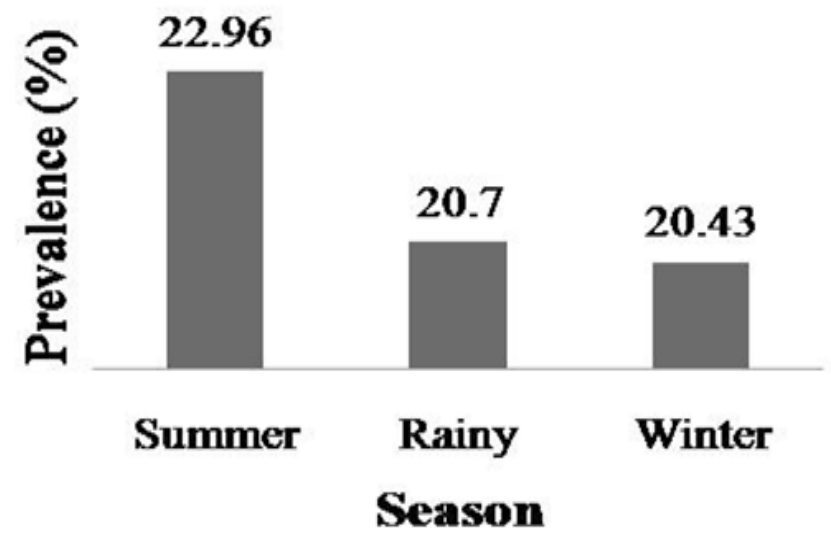

Fig. 4.Seroprevalence of REV ELISA positive chicken samples in year seasons. 


\section{Discussion}

The REV is the major immunosuppressive and economic virus in the poultry industry [14]. As the high rising poultry industry in Bangladesh need to seroepidemiological studies of REV. High prevalence of REV was found in Gazipur district. Over the country, highest densities of poultry farms were present in Gazipur district that is more than 2,651 poultry farms [15]. The high density of poultry population causes increase the rate of disease transmission as well as vector transmission [3]. Researchers have been proved that REV can harbor in the digestive system of house flies and plays a vital role as a mechanical vector for REV transmission $[16,17]$. On the other hand, only 364 poultry farms present in the Khulna district that is lowest poultry population[15].Gazipur district has a high density of house flies than Khulna district, which to increase the rate of REV transmission. As a result, comparatively Gazipur district displayed highest seroprevalence of REV than Khulna district.

All chickens of studied flocks were vaccinated with commercial available Marek'sdisease vaccine and fowlpox disease vaccine except domestic chicken flocks. Researchers have been detected the REV as a contaminant with commercial Marek's disease vaccine in Japan [18-20]and in Australia [20, 21], and also with fowlpox vaccine [22-24]. REV contaminated with this vaccine may be entered into Bangladesh is very easy, that may the cause of the presence of REV in Bangladesh.

The onset of laying at 19 to 24 weeks of age is very stressful period of poultry that increases the frequency of different diseases [25]. As our result show, the seroprevalence of REV becomes higher at onset of laying period. The maternal antibody against REV can be transmitted from hens to their day-old chicks [3, 26]. But,Gharaibeh and Mahmoud [27] demonstrated the maternal antibody titers were depletedwithin $10^{\text {th }}$ days of age in all diseases except infectious bursal disease virus. In this study, high antibody titer found against REV after $10^{\text {th }}$ days of age without vaccination of REV proved this antibody were produceddue to the response of field circulating virus [3].

Parent flocks and layer flocks are reared long times for their egg production. The study showed that broiler parent flocks, layer parent flocks and layer flocks had the highest seroprevalence, whereas broiler flocks, domestic chicken flocks and sonali chicken flocks had the lowest. This variation may be associated with the length of rearing time, that is broiler flocks and sonali chicken flocks had the shorter rearing time than other flocks $[28,29]$. REV infection rate increase according to age and it is common for a mature breeder chicken [3].Domestic chicken flocks are the native chicken of Bangladesh, rearedin backyard management system without any vaccination [30]. Thus, it has less chance to infection with possibly REV contaminated vaccine. The findings indicate that REV is also ubiquitous in all six types of chicken [3].

The present study demonstrated the highest seroprevalence in summer seasons than winter and rainy seasons. Temperature becomes rises from average and normal temperature during the summer season [31]that may induce vectors population and enhanced vector survival and replication [32]. High temperature with high humidity influences vector-borne disease transmission dynamics as well as the increased intensity of outbreak [17, 33,34]. According to geographical position and climate of Bangladesh is favorable for REV transmission.

\section{Conclusion}

From the above results of this study indicate that REV is ubiquitous in all types and age of chickens. REV infections are also widespread in summer seasons and present all over selected geographical locations of Bangladesh. It may appear as a potential threat for the rapidly growing poultry industry in Bangladesh.

\section{Recommendations}

More prevalence study, molecular characterization and vaccine production from local isolates are emergency requirements to combat REV. The quality verification of imported vaccines specially chicken pox must be strongly adopted in Bangladesh.

\section{Acknowledgements}

The author very thankful to MS Sagor, MS Hossain, M Akhtaruzzaman, M Rasheduzzaman and MSAhamed for their cordial help and directions to prepare the manuscript. This research did not receive any specific grant from funding agencies in the public, commercial, or not-for-profit sectors 


\section{Ethical approval}

All applicable international, national, and/ or institutional guidelines for the care and use of animals were followed.

\section{Conflict of interest}

The authors declare that they have no conflict of interest.

\section{References}

1. Barbacid M, Hunter E. and Aaronson S. Avian reticuloendotheliosis viruses: evolutionary linkage with mammalian type C retroviruses. J. Virol., 30, 508-514 (1979).

2. Barbosa, T., Zavala, G., Cheng, S. and Villegas, P. Full genome sequence and some biological properties of reticuloendotheliosis virus strain APC-566 isolated from endangered Attwater's prairie chickens. Virus Res., 124, 68-77 (2007).

3. Yang, Y., Zhao, J., Ma, Z., Xu, M., Xue, J. and Zhang, G. Serological survey of Reticuloendotheliosis virus infection in chickens in China in 2005 to 2015. Poult. Sci., 96, 3893-3895 (2017).

4. Cheng, Z., Shi, Y., Zhang, L., Zhu, G., Diao, X. and Cui, Z. Occurrence of reticuloendotheliosis in Chinese partridge. J. Vet. Med. Sci., 69, 1295-1308 (2007).

5. Schat, K.A., Gonzalez, J., Solorzano, A., Avila, E. and Witter, R.L. A lymphoproliferative disease in Japanese Quail. Avian Dis., 20, 153-161 (1976).

6. Trampel, D. W., Pepper, T. M. and Witter, R. L. Reticuloendotheliosis in Hungarian partridge. $J$. Wildl. Dis., 38, 438-442 (2002).

7. Lin, C.Y., Chen, C.L., Wang, C.C. and Wang, C.H. Isolation, identification, and complete genome sequence of an avian reticuloendotheliosis virus isolated from geese. Vet. Microbiol., 136,246-249 (2009).

8. Zavala, G., Cheng, S., Barbosa, T. and Haefele, H. Enzootic reticuloendotheliosis in the endangered Attwater's and greater prairie chickens. Avian Dis., 50, 520-525 (2006).

9. Puro, K.U., Ahuja, A., Joishy, T., Sen, A., Ghatak, S., Shakuntala, I. and Sunjukta, R. Molecular Detection of Reticuloendotheliosis Virus (REV) Integration in Avian Poxvirus in North Eastern India. Proceedings of the National Academy of Sciences, India Section B: Biological Sciences, 87, 273-276 (2017).
10. Kim, T.J. and Tripathy, D.N. Reticuloendotheliosis virus integration in the fowl poxvirus genome: not a recent event. Avian Dis. 45, 663-669 (2001).

11. Zhao, K., He, W., Xie, S., Song, D., Lu, H., Pan, W. and Gao, F. Highly pathogenic fowlpox virus in cutaneously infected chickens, China. Emerg. Infect. Dis.,20, 1208-1210 (2014).

12. Zhang, Z. and Cui, Z. Isolation of recombinant field strains of Marek's disease virus integrated with reticuloendotheliosis virus genome fragments. Sci. China C. Life. Sci.,48, 81-88 (2005).

13. Jiang, L., Qi, X., Gao, Y., Hua, Y., Li, K., Deng, $X$. and Wang, $X$. Molecular characterization and phylogenetic analysis of the reticuloendotheliosis virus isolated from wild birds in Northeast China. Vet. Microbiol., 166, 68-675 (2013).

14. Zeng, T., Xie, Z., Xie, L., Deng, X., Xie, Z., Luo, S. and Huang, J. Simultaneous detection of eight immunosuppressive chicken viruses using a GeXP analyser-based multiplex PCR assay. Virol. J.,12, 226 (2015).

15. Huque,S.K., Saleqque, M.A. and Rezia, K. Commercial poultry production in Bangladesh [Internet], (2016) Available from: http://wpsa-bb. com/wp-content/uploads/2016/04/Keynote-Paper7th.pdf.

16. Davidson, I. and Braverman, Y. Insect contribution to horizontal transmission of Reticuloendotheliosis virus. J. Med. Entomol., 42, 128-133 (2005).

17. Motha, M.X., Egerton, J.R. and Sweeney, A.W. Some evidence of mechanical transmission of reticuloendotheliosis virus by mosquitoes. Avian Dis., 28, 858-8567 (1984).

18. Yuasa, N., Yoshida, I. and Taniguchi, T. Isolation of a reticuloendotheliosis virus from chickens inoculated with Marek's disease vaccine. National Institute of Animal Health Quarterly, 16, 141-51 (1976).

19. Koyama, H., Suzuki, Y., Ohwada, Y. and Saito, Y. Reticuloendotheliosis group virus pathogenic to chicken isolated from material infected with turkey herpesvirus (HVT). Avian Dis., 20, 429-434 (1976).

20. Bagust, T.J. and Dennett, D.P. Reticuloendotheliosis virus: experimental infection of poultry and immunofluorescent identification of Australian isolates. Aust. Vet. J.,53, 506-8 (1977). 
21. Jackson, C.A., Dunn, S.E., Smith, D.I., Gilchrist, P.T. and Macqueen, P.A. Proventriculitis, "nakanuke" and reticuloendotheliosis in chickens following vaccination with herpesvirus of turkeys (HVT). Aust. Vet. J., 53, 457-459 (1977).

22. Fadly, A. M., Witter, R. L., Smith, E. J., Silva, R. F., Reed, W.M., Hoerr, F.J. and Putnam, M.R. An outbreak of lymphomas in commercial broiler breeder chickens vaccinated with a fowlpox vaccine contaminated with reticuloendotheliosis virus. Avian Pathol., 25, 35-47 (1996).

23. Diallo, I.S., Mackenzie, M.A., Spradbrow, P.B. and Robinson, W.F. Field isolates of fowlpox virus contaminated with reticuloendotheliosis virus. Avian Pathol., 27, 60-66 (1998).

24. Awad, A.M., Abd El-Hamid, H.S., Abou Rawash, A.A. and Ibrahim, H.H. Detection of reticuloendotheliosis virus as a contaminant of fowl pox vaccines. Poult. Sci., 89, 2389-2395 (2010).

25. Odihambo Mumma, J., Thaxton, J., VizzierThaxton, Y. and Dodson, W. Physiological stress in laying hens. Poult. Sci., 85, 761-769 (2006).

26. Sun, S.H., Cui, Z.Z. and Qu, L.X. Maternal antibody protected chicks from growth retardation and immunosuppression induced by early reticuloendotheliosis virus infection. Agri. Sci. China, 6, 762-8 (2007).

27. Gharaibeh, S. and Mahmoud, K. Decay of maternal antibodies in broiler chickens. Poult. Sci., 92, 23332336 (2013).

28. Sun, S.H., Zhao, P., Liu, S.Q. and Cui, Z.Z. Comparision on Pathogenicity of Reticuloendotheliosis Virus to Different Ages' SPF Chickens [J]. Chinese J. Anim. Vet. Sci., 6, 023 (2010).
29. Xue, Q., Zhang, G., Li, T., Ling, J., Zhang, X. and Wang, J. Transcriptomic profile of leg muscle during early growth in chicken. PloS one, 12, e0173824 (2017).

30. Das, S., Chowdhury, S., Khatun, M., Nishibori, M., Isobe, N. and Yoshimura, Y. Poultry production profile and expected future projection in Bangladesh. World's Poult. Sci. J., 64, 99-118 (2008).

31. Jupp, P.G., Blackburn, N.K., Thompson, D.L. and Meenehan, G.M.. Sindbis and West Nile virus infections in the Witwatersrand-Pretoria region. $S$. Afr. Med. J., 70, 218-220 (1986)

32. Chase, J.M. and Knight, T.M. Drought-induced mosquito outbreaks in wetlands. Ecol. Lett., 6, 1017-1024 (2003).

33. Gubler. D.J. Prevention and control of tropical diseases in the 21st century: back to the field. Am. J. Trop. Med. Hyg., 65, v-xi (2001).

34. Epstein, P.R., Diaz, H.F., Elias, S., Grabherr, G., Graham, N.E., Martens, W.J. and Susskind, J. Biological and physical signs of climate change: focus on mosquito-borne diseases. Bulletin of the American Meteorological Society, 79, 409-417 (1998).

(Received 25/10/2018; accepted $11 / 12 / 2018$ ) 


\section{دراسة الانتشار المصلي للعدوى الفيروسية للشبكية في الاجاج في بنجلاديش محمد ذو الفقار علي

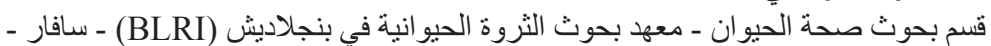

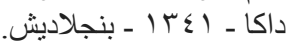

أظهرنا الانتشار المصلي لفيروس Reticuloendotheliosis (REV) في الدواجن في مناطق مختارة من

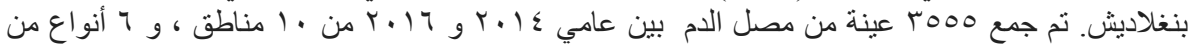

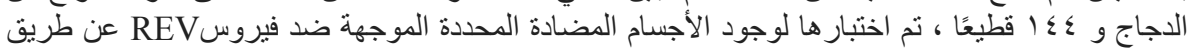

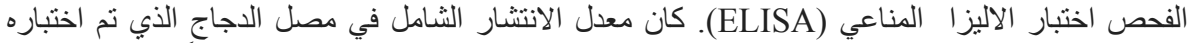

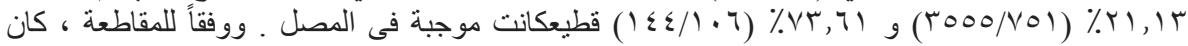

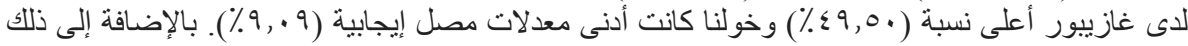

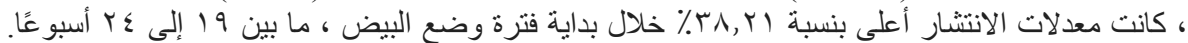

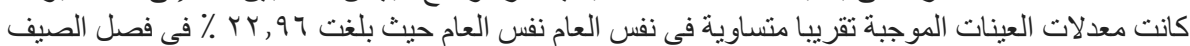

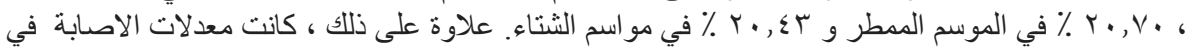

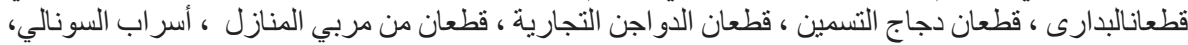

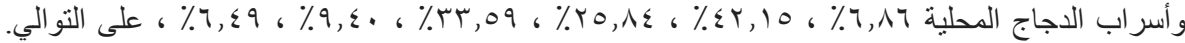

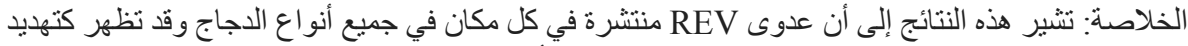

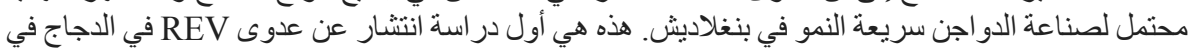

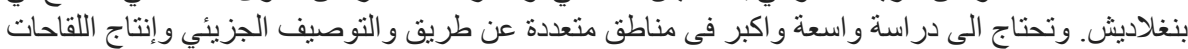

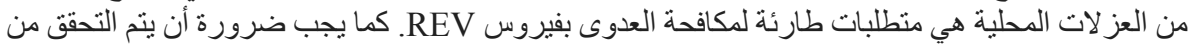

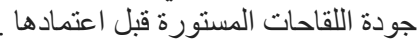

الكلمات الدالة :Reticuloendotheliosis، REV ، الانتشار المصلي ، الأجسام المضادة ، الدجاج ، ELISA

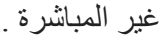

